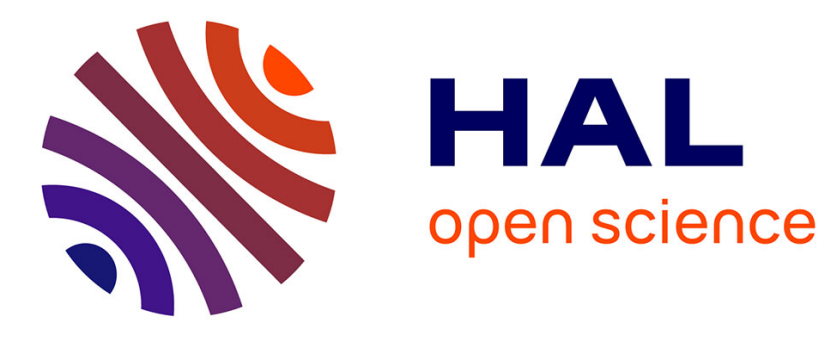

\title{
Shining the light to terahertz spectroscopy of nL-volume biological samples
}

\author{
Sergey I. Mitryukovskiy, Melanie Lavancier, Flavie Braud, Goedele Roos, \\ Theo Hannotte, Emmanuel Dubois, Jean-Francois Lampin, Romain Peretti
}

\section{- To cite this version:}

Sergey I. Mitryukovskiy, Melanie Lavancier, Flavie Braud, Goedele Roos, Theo Hannotte, et al.. Shining the light to terahertz spectroscopy of nL-volume biological samples. CLEO (The Conference on Lasers and Electro-Optics Conference) 2019, May 2019, San Jose, United States. paper ATu3K.6, 2 p., 10.1364/CLEO_AT.2019.ATu3K.6 . hal-02158865

\section{HAL Id: hal-02158865 https://hal.science/hal-02158865}

Submitted on 18 Jun 2019

HAL is a multi-disciplinary open access archive for the deposit and dissemination of scientific research documents, whether they are published or not. The documents may come from teaching and research institutions in France or abroad, or from public or private research centers.
L'archive ouverte pluridisciplinaire HAL, est destinée au dépôt et à la diffusion de documents scientifiques de niveau recherche, publiés ou non, émanant des établissements d'enseignement et de recherche français ou étrangers, des laboratoires publics ou privés. 


\title{
Shining the Light to Terahertz Spectroscopy of nL-Volume Biological Samples.
}

\author{
Sergey Mitryukovskiy ${ }^{1, *}$, Mélanie Lavancier ${ }^{1}$, Flavie Braud ${ }^{1}$, Goedele Roos ${ }^{2}$, Théo Hannotte ${ }^{1}$, \\ Emmanuel Dubois ${ }^{1}$, Jean-François Lampin ${ }^{1}$ and Romain Peretti ${ }^{1}$ \\ ${ }^{1}$ Institute of Electronics, Microelectronics and Nanotechnology (IEMN), CNRS/Univ. Lille, \\ Avenue Henri Poincaré CS 60069, 59652 Villeneuve-d'Ascq Cedex, France \\ ${ }^{2}$ Unit of Structural and Functional Glycobiology (UGSF), CNRS/Univ. Lille, \\ *sergey.mitryukovskiy@iemn.fr
}

\begin{abstract}
We present a technique allowing the confinement of a broadband terahertz pulse to a few$\mathrm{nL}$ volume. The method is approved in terahertz time-domain spectroscopy study of biological samples and further perspectives are discussed.

OCIS codes: $300.6495,170.6510$.
\end{abstract}

Terahertz (THz) radiation, being non-invasive and non-ionizing, attracts wide attention due to its unprecedented sensing capacities. Recent progress in instrumentation has leaded to impressive breakthroughs in $\mathrm{THz}$ applications in biomedical research [1]. Vibrational states of many biological molecules correspond to a spectral range extending from mid-infrared to terahertz. THz spectroscopy has been exploited to detect, identify and study various biomaterials: nucleic acids [2], proteins [3], amino acids and polypeptides [4], etc. However, the quantity of a biological sample is usually limited to a few $\mu \mathrm{g}$ if not to a few molecules. Confining light in a subwavelength volume increases light matter interactions. This is of utmost importance for bio samples due to the small size - its volume is usually smaller than the cube of the THz wavelength, thus the light-matter interactions are extremely reduced. Such confinement can be done in high refractive index material by using a photonic-crystal structure, for instance. However, it is more challenging in low refractive index medium such as biological samples. In the THz spectral range this had been achieved using near field microscopy [5] or wave guiding structures that confines the light in one direction using a parallel plate metallic waveguide (PPMW) [6] ideal for time-domain spectroscopy (TDS) [7] experiments. However, a specific coupling scheme is needed to properly excite the mode of interest. Our method combines the curved tapered antenna approach similarly to [8] with the approach of [9] using a fully planar geometry and a subsequent 2D confinement. Due to its final shape and geometry, we named our exponential tapered antenna coupled metallic waveguide as "Butterfly". The conception was discussed for the first time last year [10], here we will present the complete design, fabrication and application of our technique to biological sample of minor volume. We present the capacity of the method for THz TDS of a few-nL-volume organic sample, and further use the method to study biological compounds applied in pharmacological research.

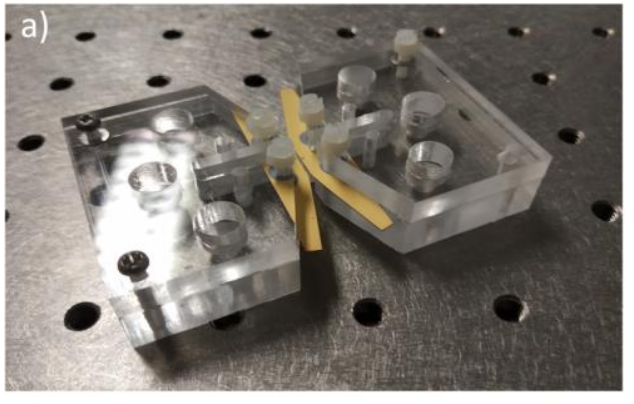

c)

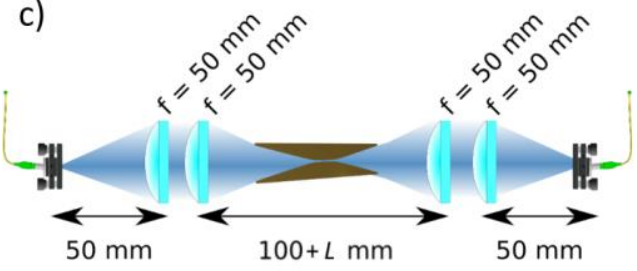

b)

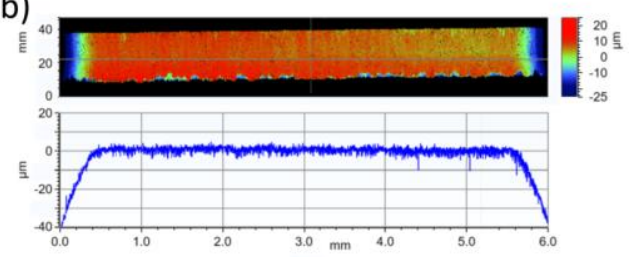

d)

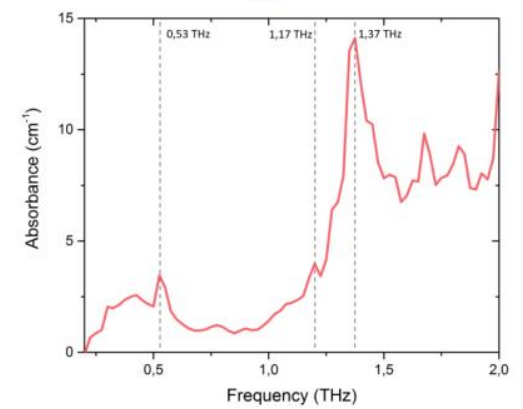

Fig. 1. (a) Photo of the device used for the confinement of THz radiation. The transparent plaastic structures serve as a holder for the device, allows an easy fixation on the experimental set-up, control of the waveguide width, and prevents from damages. (b) Typical profile of the wavegide surface measuerd with Bruker Contour GT-X optical profilometer. (c) Schematic of the experimental set-up, $L$ serves for the length of the waveguide. (d) Spectrum of the absorbance of $15-\mu \mathrm{g}$ lactose powder sample. 
Several butterfly devices with various waveguide length $(0.5-10 \mathrm{~mm})$ were fabricated from $300-\mu \mathrm{m}$-thick silicon wafers using laser cutting allowing an improvement of the sidewall roughness (average arithmetical mean deviation $\left.R_{a} \sim 1.5 \mu \mathrm{m}\right)$ and reduce in the production cost. The butterfly was covered by Ti/Au layer by means of sputtering. The gold layer thickness inside the waveguide is $\sim 500 \mathrm{~nm}$. The TDS experiments was done using a Menlo TeraSmart system. The typical butterfly device, waveguide profile trace and the schematics of the set-up are shown in Fig. 1.(ac). To test the capacity of our method we probed a minor-volume sample of lactose powder, the total sample volume inside the waveguide is estimated as $10 \mathrm{~nL}(\sim 15 \mu \mathrm{g})$. The absorption spectrum is presented in Fig. 1.(d), there the $0.53 \mathrm{THz}, 1.17 \mathrm{THz}$ and $1.37 \mathrm{THz}$ characteristic absorption lines of lactose [11] are well observed. We thus expect that our technic will be efficient even for lower sample quantities.

We further apply the method to study biological molecules used in medical and pharmaceutical research. In particular, we obtained the THz spectrum of the inhibitor of transforming growth factor $\beta$ receptor I (TGF $\beta$ RI/Alk5), BI-4659 compound by Boehringer Ingelhaim. TGF $\beta$ RI is a membrane-bound receptor protein for the transforming growth factor $\beta$ (TGF $\beta$ ) superfamily of signaling ligands. TGF $\beta$ is a pluripotent cytokine involved in the regulation of various biological processes such as cell proliferation, differentiation, migration, adhesion, apoptosis, and epithelialto-mesenchymal transition. Therapeutic approaches to inhibit its signaling by targeting TGF $\beta$ receptor I (TGFBRI/Alk5) are discussed for the treatment of diseases such as idiopathic pulmonary fibrosis (IPF) and cancer [12]. BI-4659 is a potent inhibitor of TGFßR1 with an $\mathrm{IC}_{50}$ value of $19 \mathrm{nM}$ and shows selectivity against a broad panel of other kinases. The recorded spectrum is shown in Fig. 2. alongside the schematic chemical structure of the BI-4659 molecule, revealing possible characteristic $\mathrm{THz}$ fingerprints. To approve our findings we are currently doing theoretical calculations and modelling using density functional theory (DFT) and the Fit@TDS software [13], the complete results will be presented during the conference.
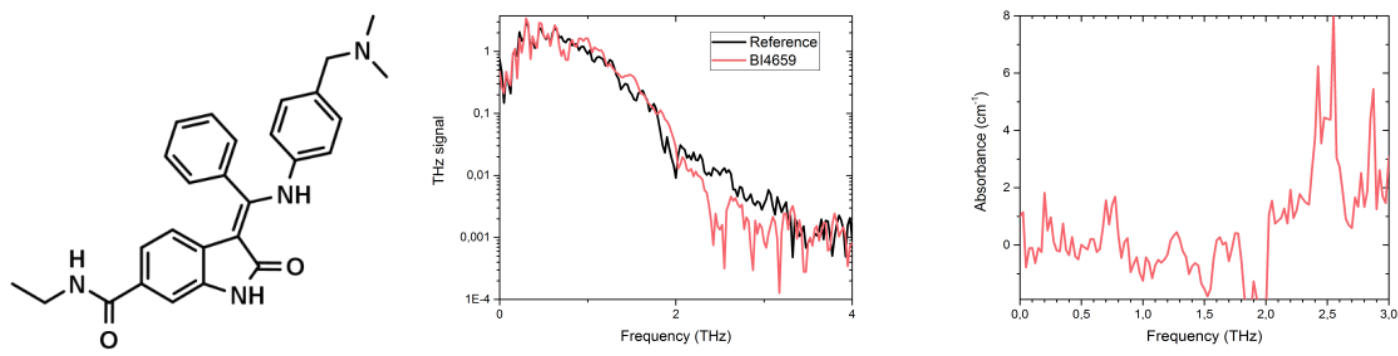

Fig. 2. (a) Schematic chemical structure of BI-4659 compound (TGF $\beta R I$ inhibitor). (c) Spectrum of the absorbance of 10-nL BI-4659 sample.

To summarize, we mastered a technique for broadband $\mathrm{THz}$ pulse confinement to a few-nL volume using an exponential tapered antenna coupled metallic waveguide. The method allowed us to observe for the first time $\mathrm{THz}$ spectrum of the TGFßRI/Alk5 inhibitor, BI-4659 compound that is of a high interest in pharmacological research. With our method, we have a powerful tool for TDS-THz characterization of biological molecules, we are currently applying it to a wide number of bio molecules and the results will be presented during the conference.

This work was supported in part by the International Chair of Excellence "ThOTroV" from region "Hauts-de-France," in part by the Welcome Talent Grant "NeFiStoV" from the European Metropole of Lille, in part by the "TeraStoVe" from I-site ULNE, and in part by the French Government through the National Research Agency under Program PIA EQUIPEX ExCELSiOR ANR 11-EQPX-0015.

\section{References}

[1] X. Yand. et al., "Biomedical applications of terahertz spectroscopy and imaging," Trends in Biotechnology 34, 810-824 (2016).

[2] E. Castro-Camus, et al., "Conformational changes of photoactive yellow protein monitored by terahertz spectroscopy," Chem. Phys. Lett. 455, 289-292 (2008).

[3] G. Acbas, et al, "Optical measurements of long-range protein vibrations," Nature Comm. 5, 3076 (2014).

[4] K. Yamamoto, et al., "Terahertz Time-Domain Spectroscopy of Amino Acids and Polypeptides,” Biophys. J. 89(3), 22-24 (2005).

[5] S. Mastel, et al., "Terahertz nanofocusing with cantilevered terahertz-resonant antenna tips," Nano Lett. 17, 6526-6533, (2017).

[6] R. Mendis and D. Grischkowsky, "Undistorted guided-wave propagation of subpicosecond terahertz pulses," Optics lett. 26, 846-848 (2001).

[7] M. Van Exter, et al., "Terahertz time-domain spectroscopy of water vapor," Optics lett. 14, 1128-1130 (1989).

[8] A. J. Shutler and D. Grischkowsky, "Gap independent coupling into parallel plate terahertz waveguides using cylindrical horn antennas," Journal of Applied Physics 112, 073102 (2012).

[9] C. L. C. Smith, et al., "Efficient excitation of channel plasmons in tailored, uv-lithography-defined v-grooves," Nano lett. 14, 1659 (2014).

[10] R. Peretti, et al., "Broadband terahertz light-matter interaction enhancement for precise spectroscopy of thin films and micro-samples," MDPI Photonics 5, 11 (2018).

[11] L. Dong-Kyu, et al., "Highly sensitive and selective sugar detection by terahertz nano-antennas," Scientific Reports 5, 15459 (2015).

[12] C. Neuzillet, et al., "Targeting the TGF $\beta$ pathway for cancer therapy," Pharmacology \& Therapeutics 147, 22-31 (2015).

[13] R. Peretti, et al., "THz-TDS time-trace analysis for the extraction of material and metamaterial parameters", IEEE Trans. Terahertz Sci.

Technol. 9, 136 (2019). 